Artículo derivado de la investigación "La muerte en la novela colombiana: entre la plenitud y el escepticismo en Las noches todas de Tomás González y Memorias de un hombre feliz de Darío Jaramillo Agudelo", presentada para optar al título de Magister en Literatura y Cultura (Instituto Caro y Cuervo, 2019).

Cómo citar este artículo: Rondón Vélez, P. (2020). La muerte: entre la plenitud y el escepticismo en Las noches todas de Tomás González y Memorias de un hombre feliz de Darío Jaramillo Agudelo. Estudios de Literatura Colombiana 47, pp. 73-92. DOI: https://doi.org/10.17533/udea.elc.n47a04

1 https://orcid.org/0000-0003-2087-8681 peter.rondon@caroycuervo.gov.co Instituto Caro y Cuervo, Colombia

Editores: Andrés Vergara Aguirre, Christian Benavides Martínez, Valentina Noreña Gómez

Recibido: 15.02 .2020

Aprobado: 11.05 .2020

Publicado: 23.06.2020

Copyright: (2020 Estudios de Literatura Colombiana. Este es un artículo de acceso abierto distribuido bajo los términos de la Licencia Creative Commons AtribuciónNo comercial - Compartir igual 4.0 Internacional

\section{LA MUERTE: ENTRE LA PLENITUD Y EL ESCEPTICISMO EN LAS NOCHES TODAS DE TOMÁS GONZÁlEZ Y MEMORIAS DE UN HOMBRE FELIZ DE Darío Jaramillo Agudelo*}

\author{
Death: Between the Plenitude and the \\ Scepticism in LAS NOCHES TODAS BY Tomás \\ GonZÁlez AND MEMORLAS DE UN HOMBRE \\ feliz by Darío Jaramillo Agudelo \\ Peter Rondón Vélez ${ }^{1}$
}

Resumen: el artículo analiza la dimensión estética y filosófica de la muerte en Las noches todas de Tomás González y Memorias de un hombre feliz de Darío Jaramillo Agudelo. En este sentido, muestra cómo la posición de los narradores está mediada por una consciencia de finitud que afecta su representación del mundo, y configura un tipo de novela que se aleja del escepticismo e incorpora la plenitud, para descubrir nuevas modulaciones del morir. Finalmente se apunta la necesidad de iniciar una historia de la muerte en la literatura colombiana.

Palabras clave: la muerte; Las noches todas; Tomás González; Memorias de un hombre feliz; Darío Jaramillo Agudelo; novela colombiana; escepticismo; plenitud.

Abstract: This paper analyzes the esthetic and philosophical dimension of death in Las noches todas by Tomás González and Memorias de un hombre feliz by Darío Jaramillo Agudelo. For this reason, it shows how the position of the narrators is mediated by an awareness of death that affects their representation of the world, and sets up a type of novel that departs from scepticism and incorporates plenitude, to discover new modulations of death. Finally, the need to start a history of death in Colombian literature is noted.

Keywords: The Death; Las noches todas; Tomás González; Memorias de un hombre feliz; Darío Jaramillo Agudelo; colombian novel; scepticism; plenitude. 
Muchos mueren demasiado tarde, y algunos mueren demasiado pronto.

Todavía suena extraña esta doctrina: "iMuere a tiempo!" [...].

Todos dan importancia al morir: pero la muerte no es todavía una fiesta.

Los hombres no han aprendido aún cómo se celebran las fiestas más bellas. Yo os muestro la muerte consumadora, que es para los vivos un aguijón y una promesa $[\ldots .$.$] . Tanto al combatiente como al victorioso les resulta odiosa esa$ gesticuladora muerte que se acerca furtiva como un ladrón [...]

Yo os elogio mi muerte, la muerte libre, que viene a mí porque yo quiero Asíbabló Zaratustra, Friedrich Nietzsche

El hombre puede definirse como un ser social, pero es ante todo un ente biológico que se ciñe a la finitud. Tal condición marca su conciencia sobre la vida tanto en el ámbito personal como en el espacio social, donde adquiere costumbres y tradiciones que se traducen en las formas de espiritualidad adoptadas frente al suceso y en su representación a través de la pintura, la escultura, la fotografía y la escritura. Siguiendo a Ruiz Vásquez (2014), al comportar una dimensión individual y colectiva, la muerte toca el instrumento de sociabilidad más antiguo: la lengua. El hombre es un ser del hablar y, por tanto, la lengua refleja los imaginarios que la nutren; a través de rituales o de la literatura —entendida como transformación del mundo en lenguaje-, morir adquiere un modo particular de expresión en cada país.

$\mathrm{Al}$ entender que el fenómeno literario no es un espejo, sino una refracción compleja que plantea visiones de mundo, a partir del entramado social del cual surge, no resulta extraño el maridaje entre un hecho biológico y las letras; no se busca estudiar lo primero por medio de las imágenes que plantea la segunda, sino revisar qué papel juega la muerte en la narrativa colombiana. Se trata de un hecho inherente a la condición humana, clave por su carga emocional y aparecer constante en la novela, que no se explica solo porque nuestra historia contenga una larga cadena de conflictos. Tal condición, lejos de plantear una construcción nacional signada por lo trágico, no revela cuáles son los sentidos que se le asignan. Pese a que la muerte como tema es universal, no lo es la experiencia singular que produce en un pueblo; por lo tanto, aunque sus imaginarios se han nutrido de la tragedia, tiene una estética diferente a la planteada en otras regiones narrativas.

Este trabajo examina en Las noches todas (2018), de Tomás González, y Memorias de un hombrefeliz (2000), de Darío Jaramillo Agudelo, cómo está determinada la consciencia de los personajes por la prenuncia tanática; la copresencia vida-muerte y juventud-vejez, 
aunada a la relación con el paisaje y la soledad, construye una representación del mundo mediada por la cercanía o la distancia con el final. De esta forma, lejos de plantear un discurso mediado por el dolor, conciben plenitud en el suceso.

Las novelas de González abordan problemas actuales como la violencia, la migración forzada o los altibajos de la economía, sin nombrarlos directamente; tales sucesos se dan de manera intemporal, sin detenerse en la espectacularidad o la presunta novedad de lo aparente. El escritor transita un camino sinuoso donde la muerte se aleja del tono negativo y asume una mirada versátil que explora los duelos en los que se van hundiendo los vivos ante la pérdida del ser querido, los ritos que ayudan a aceptar el hecho o la enfermedad y la vejez como estados terminales de lo humano. Ejemplo de ello es Las noches todas, obra en la que un anciano abandona la ciudad y crea un paraíso adánico donde se conjuga el amor libidinoso con la proximidad de la muerte. Los alientos se le agotan a medida que cada mañana cruza un jardín mirando qué plantas sembrar o cómo recobrar una belleza primigenia en el paisaje sin que parezca decisión suya. Al final, la vegetación que inundó su sed de creador se convierte en etapa pasajera para alguien cercano al ocaso de la vida.

Por su parte, Memorias de un hombre feliz descubre la muerte en triple instancia: asesinato, suicidio y espera. Tomás, despótico a primera vista, propicia odio hacia su esposa. La traslación entre el cuerpo enfermo de la mujer y la recuperación de su libertad, manifiesta un proceder violento y una relación de poder macabra que retrata la tensión física y emocional del protagonista. Sin dejar de mostrar el intimismo que comprende la muerte, la novela presenta el culto social que esta propicia cuando familiares y amigos contemplan el deterioro paulatino de Regina, mientras su marido modifica la idea clásica del matrimonio, "hasta que la muerte los separe", al interpelarla como la opción de anular un ser que le provoca un profundo malestar.

En ambas novelas se concibe la muerte como un largo proceso y que vivir es morir, un coexistir entre dos posiciones que determinan en diverso grado las narraciones, e impactan el destino de los personajes, de acuerdo a su filiación con el jardín, el amor o la sensación de longevidad. Sus interpretaciones exploran otras alternativas del suceso y huyen de terminologías maniqueas. Tal consideración ubica las obras en una tradición más extensa; en el sistema de relaciones literarias, los dos títulos permiten considerar la importancia del tema para otros escritores. Acercarse a sus visiones destaca la necesidad de una historia 
que indague cómo varían los significados de la muerte y qué valores comporta; en otras palabras, qué relación hemos tejido con ella y qué elementos se consideran al representarla.

\section{La dimensión estética de la muerte}

Examinar las concepciones de la muerte es rastrear también su estética, pues "el valor estético se relaciona no con cierta disposición del material o con cierto funcionamiento autotélico, autárquico, del material verbal de la obra, sino con cierta puesta en forma, cierta ‘evaluación’ del mundo” (Goldman, 1971, p. 37) que se vale de lo lingüístico para expresarse y lo desborda, pues las visiones de un grupo son plasmadas en las diferentes actividades que este lleva a cabo. El novelista emprende una re-creación de esos valores y da el paso de la esfera colectiva a la individual; por tanto, su mirada denota apreciaciones de la muerte debido a las implicaciones culturales del hecho que él retoma en su relato. Consecuentemente, estudiar ciertas novelas que integran el corpus narrativo de una sociedad permite dilucidar cómo las visiones de mundo influyen en la estética con la cual se configura un tema en particular.

Pese a ser un hecho natural, la muerte "constituye un continuo motivo de inaliviable tormento. Ignoramos de dónde puede venir y volvemos sin cesar la cabeza a todos lados, como en comarca peligrosa” (Montaigne, 1984, p. 49), en un frenesí por entenderla. Dadas sus diferentes causas y consecuencias, su aprehensión ontológica implica auscultar sus significantes; ella "adquiere el sentido que los hombres le confieren: un sentido social, un sentido de institución cada vez diferente de una sociedad a otra, para conjurarle el horror (toda cultura es [...] una tentativa por domeñar la muerte)" (Redeker, 2018, p. 31); sentido definido principalmente en el plano religioso o filosófico, sin olvidar que

Nadie puede tomarle a otro su morir. Cabe, sí, que alguien "vaya a la muerte por otro", pero esto quiere decir siempre: sacrificarse por el otro en una cosa determinada. Tal "morir por..." no puede significar nunca que con él se le haya tomado al otro lo más mínimo su muerte. El morir es algo que cada "ser ahí" tiene que tomar en su caso sobre sí mismo (Heidegger, 1993, p. 262).

A pesar de estar vedada su experiencia, el ser reflexiona alrededor de la muerte cuando es ajena. Sin embargo, no experimentar en su genuino estado el morir de alguien, 
limitándose a asistir como espectador y ente sensible al impacto de la cercanía con el cadáver, permite construir una idea en términos de colectividad, ya que, como clarifica Heidegger, el ser es esencialmente ser por su relación con los otros, y la "pérdida" que involucra el deceso la padecen quienes perviven (p. 229). Tal simbiosis social exime del acto y brinda acceso a él, por medio de lo observable en el entorno y los significantes heredados. Bajo esta perspectiva, la literatura testimonia intuiciones particulares de la muerte que pueden extrapolarse a ámbitos generales, pues, de acuerdo con Carl Rogers, "las cosas más personales son compartidas universalmente" (citado por Lederach, 2016, p. 19).

La literatura cierra la brecha entre la muerte externa y la propia; más allá de recrear el morir de los personajes, les traza propósitos, los recubre de esperanzas y los integra a un escenario que sucumbe ante su ausencia; los convierte en arquetipos ${ }^{1}$ y retrata claridades que el lector no ha conseguido articular. Vemos en ellos aquello asumido como regla general y procuramos adjudicarles formas de fallecer acordes con tradiciones y costumbres conocidas; la catarsis es fuerte cuando su actuar no dista mucho de lo que puede ocurrirle a cualquier ser humano. Al leer, "hallamos aquella pluralidad de vidas que nos es precisa. Morimos en nuestra identificación con el protagonista, pero le sobrevivimos y estamos dispuestos a morir otra vez, igualmente indemnes, con otro" (Freud, 1981, p. 2111).

En el caso colombiano, la narrativa sobre la muerte no involucra, necesariamente, una incorporación directa de la filosofía o la religión, pese a que tales instancias surjan al interpretar la obra, y en cambio se declara un marcado tinte social y político. Se recurre menos al monólogo interno de largo aliento y se acerca más a la esfera emocional. Los autores desglosan sus diferentes facetas y develan cómo se inserta en cada estrato de la vida; cuando un personaje muere, o está próximo a hacerlo, puede exaltar los ideales de nación, visibilizar aquel acto como herramienta de control, exponer la ansiedad que genera su inminencia o poner de manifiesto cómo su leitmotiv está mediado por la fatalidad. En cualquier caso, la novela atestigua una

1 Los arquetipos representan contenidos del inconsciente colectivo que determinan multitud de comportamientos y acciones. Acumulados en la memoria histórica del género humano, están impregnados de matices tan variados como la religión, la mitología, los valores, las costumbres y las creencias. Finalmente, su forma de activación obedece al principio de compensación, es decir, los arquetipos residen en el inconsciente colectivo, pero solo se activan en los sujetos en virtud de su situación psicosocial (Saiz, Fernández y Álvarez, 2007, p. 4). 
progresión temática en virtud de la dimensión cultural, política, económica y social que tiene la muerte en el país. ${ }^{2}$

Ahora bien, encarar la muerte cobra mayor valor según la cercanía del personaje con la misma. La vejez, por ejemplo, brinda asociaciones diferentes a las que se darían si la voz narrativa partiera de un niño o un adolescente; los protagonistas de González y Jaramillo Agudelo devuelven a la novela un estatuto de poder que permite solidarizarse con el morir de dos hombres y encontrar en el libro una desacralización del recinto mortuorio. Al decir de Robert Redeker (2018), "la tumba de las letras no es de la misma naturaleza que la tumba de piedra. Los cuerpos y los restos han sido absorbidos por la materia literaria, fusionándose con ella” (p. 104). Fuera del libro los filósofos sucumben ante el paradigma científico, pero en su interior manipulan la muerte para asignarle valores que no tiene en la realidad, hacen posible sentir emociones ausentes en las definiciones técnicas y brindan conjeturas plausibles para enfrentar los temores que genera.

Asumir que los muertos son construcciones de los vivos convierte a la novela en profanación no para clausurar su sentido, sino para descubrir qué se puede esperar de la muerte como hecho irrevocable. En ese sentido, en la necesidad de generar disposiciones simbólicas desmarcadas de lo positivo o lo negativo, se retoman las propuestas de Tomás González y Darío Jaramillo Agudelo para evidenciar la amalgama que soporta el tema.

\section{Las noches todas}

Después de jubilarse como docente universitario, Esteban Latorre se muda a una pequeña finca y disminuye sus relaciones con los demás. Allí vivirá con la idea de crear un jardín que represente su ideal de belleza, y se preguntará si el esplendor que desea alcanzar justifica su existencia y el sufrimiento que le provoca. Refugiado en la

2 Prueba de ello son las obras decimonónicas como María (1867) de Jorge Isaacs, Dolores (1867) de Soledad Acosta de Samper o El poeta Soldado (1881) de José María Samper. En el siglo xx, Sin tierra para morir (1954) de Eduardo Santa, Raza de Cain (1954) de Gustavo Zola y Ponce, La rebelión de las ratas (1960-1961) de Fernando Soto Aparicio, La casa grande (1962) de Álvaro Cepeda Samudio, Cóndores no entierran todos los días (1972) de Gustavo Álvarez Gardeazábal, gran parte de la obra de García Márquez — por ejemplo, El otoño del patriarca (1974) y Crónica de una muerte anunciada (1981) —, El cadáver (1975) de Benhur Sánchez, Crónica de tiempo muerto (1975) de Óscar Collazos, o En diciembre llegaban las brisas (1987) de Marvel Moreno. Así mismo, autores entre los que destacan Álvaro Salom Becerra, Germán Espinosa o Fernando Vallejo, y géneros como la sicaresca, la novela urbana o la novela negra. En definitiva, este boceto del cuadro literario nacional constata el amplio número de textos donde la muerte aborda varios horizontes de lo humano. 
vegetación, descubrirá un doble fracaso: la imposibilidad de domesticar la naturaleza y la incapacidad de separarse del mundo. Su conflicto es doloroso cuando intenta mantenerse activo en la senectud.

No resulta extraño comprender la novela, siguiendo las ideas de Óscar Daniel Campo Becerra (2012), como los caminos que recorren los personajes hacia el cumplimiento de su destino trágico, tránsito en el que fundan una realidad estética particular, "condenados no porque deban morir, sino porque su conciencia de la muerte intensifica el sentido de la vida y vuelve terrible la idea de su propia extinción” (p. 179). Aunque Esteban se sabe cercano a su final, pretende sortearlo al dedicarse a la jardinería, al yoga o dando lugar a pasiones que creía superadas. La anhelada soledad le será esquiva desde un primer momento cuando conoce al taxista Misael y se obsesiona con sus historias sin desenlace, pasando por el vecino Ezequiel, los trabajadores que ayudan a convertir el patio en selva, junto a las deterioradas relaciones con Victoria, su exesposa, y Cristina, su hija; círculo de lazos interpersonales en el cual destacan dos mujeres.

La belleza y energía de Aurora es análoga a la insistencia de Esteban por mantenerse activo. Ella toma las decisiones de los asuntos domésticos y crea un estilo diáfano en el jardín, para descubrir un lugar sin aparente intervención humana; su forma de pensar y actuar la insertan más a la vida. Carmelita, por el contrario, mayor que Esteban, señala la proximidad de la muerte; una mujer terca que siempre lo acompañó y lo continuó visitando al trasladarse a un hogar de retiro, "como si ella fuera más joven [...] como visitando a un anciano” (González, 2018, p. 206):

Yo había conocido a Aurora en un retiro para practicantes de Yoga. Llevaba mucho tiempo desempleada o parcialmente empleada, igual que medio país, de modo que le ofrecíun salario por su trabajo con las plantas y también para que siguiera enseñándome aquella antiquísima disciplina que me mantendría sano y atento y aumentaría mis probabilidades de vivir el tiempo que necesitaba para terminar el asunto [el jardín]. Una señora ya bastante mayor, Carmelita - a quien yo conocía desde la infancia y era casi una tía o una prima, pues había trabajado de niña con mi abuela y de joven con mis tías, ya difuntas todas - se encargaba de los trabajos domésticos (p. 39).

Mientras Aurora se desentiende del mundo y piensa poco en los problemas familiares o en los cadáveres que ocasionalmente navegan los ríos, Carmelita mantiene el vínculo con la realidad al informar sobre los cuerpos flotantes, la muerte de Ezequiel, las amenazas 
del yerno y su repentina aparición en una morgue tras varios días desaparecido, o los nuevos proyectos inmobiliarios alrededor de la propiedad. Dibujadas así, la pareja de mujeres expresa diferentes niveles de cercanía con la vida. Tal condición se explica porque en González la figura femenina está más cerca de lo práctico y demuestra un carácter contrario al de los hombres, capaces de construir una casa a la orilla del mar - Primero estaba el mar (1983) - levantar una finca en las montañas - Los caballitos del diablo (2003) — , o pintar un cuadro mientras se espera la noticia de la muerte asistida de un hijo — La luz difícil (2011) —, pero no se muestran hábiles en sus maneras de sobrellevar los vínculos familiares. No saben reaccionar a los problemas $y$, ante esa indefensión, deciden ensimismarse, acosados por una idea obsesiva de la muerte, la belleza y la plenitud. Las mujeres expuestas a tal autodestrucción tienden a huir. Aurora no es la excepción. Después de apoyar varias remodelaciones de la casa para integrarla al edén, se casará con Javier Aguirre, un arquitecto que secundó la odisea. Esta partida no romperá la unión entre los personajes, que seguirán comunicándose, pues no parecían “sentir la necesidad de ver al otro, pero sí de saber del otro"(González, 2018, p. 206). Por lo tanto, Aurora afirma una tendencia a la conservación, como se aprecia cuando miran el río y aparece un cadáver que revela su estado anímico:

\footnotetext{
Salimos con trabajo de entre el apretado gentío y, al llegar a la casa, Aurora se puso a llorar. No lloraba por lo que había visto, decía, sino por ella misma. Lloraba porque cadáver y gallinazo la habían dejado indiferente. Porque se sentía como muerta. Y allí tal vez estaba lo que muchos consideraban un misterio y aquello de lo que ella se estaba refugiando (p. 79).
}

Para ella el jardín es un escondite que le permite evadir la realidad y ocultar la muerte, mientras a Esteban se le ofrece como una ruta de retraso; él vive los cambios que llegan con la edad y adapta el espacio a sus preocupaciones de hombre mayor. De tal forma, "parece buscar en la soledad del campo [...] un lugar de inspiración y de sosiego que hasta entonces no ha alcanzado" (Salamanca, 2019, p. 237). Actitud presente desde las primeras páginas cuando decide "comprar una casa con buen terreno para [...] vivir en silencio con la tierra y las matas" (González, 2018, p. 9). Esta configuración del campo como hábitat ambiguo que beneficia el deseo de ambos personajes, coloca a tánatos en la distancia y permite ver que: 
González no habla directamente de los temas de violencia en el campo, pero tampoco abandona el campo como espacio narrativo. Aparece otro tipo de violencia que arrastra una parte importante de los personajes. Para el antioqueño, el campo cobra una nueva significación, sobre todo en su contraste forzoso con la ciudad y en la visión renovada que del mismo se ofrece (Báez León, 2013, p. 207).

Al abandonar el entorno urbano, Esteban escapa del caos para buscar lo puro. Dicha migración lo enfrenta a una característica del espanto: "mientras más bello, más monstruoso el monumento" (González, 2018, p. 74). Esta copresencia de felicidadtristeza y belleza-horror impide al protagonista huir del razonar nervioso que determina a los hombres en la novelística de González y los arrastra a la aniquilación por fuerzas que no controlan, pero ayudan a crear. En tal ambivalencia, los ambientes naturales juegan un papel fundamental al perturbar las emociones y afectar las conductas. De acuerdo con el escritor, los "escenarios abren en los personajes una nueva manera de ser, de estar en el mundo. En mis novelas no hay personajes sin escenario ni escenario sin personajes. No serían novelas en ninguno de los dos casos"(Quintana y Díaz, 2018).

A medida que el anciano y la joven transforman sus modos de ser, el crecimiento o deterioro de las plantas acompaña esos cambios y se mezcla con sus sentimientos. La naturaleza evidencia que el "jardín, como la vida, es siempre un ejercicio inconcluso. Se trata en efecto de una práctica que por su constante transformación adquiere un sentido circular y que aspira así a la inmortalidad"(Salamanca, 2019, p.239). La tensión entre vida y muerte crea un espacio donde el narrador dota de mayor sentido la ficción instaurada con el vuelo de insectos y el plegar de las flores, en clara referencia a su empeño de alcanzar una esencia de lo real que se ve limitada por la condición de finitud:

Parecía una selva, sí, pero como pensada para un estudio de cine. Era como si los insectos que entraran en ella se volvieran de cartón al cruzar la frontera y siguieran volando ya muertos. El artificio lo empapaba todo. $\mathrm{Y}$ otra vez mi mente formaba la imagen de la cuadrilla de obreros acabando con ese arrume de matas vivas, pero $\tan$ falsas como si fueran de tela, de piedras puestas, de ruinas que se habían vuelto también falsas (González, 2018, p. 64).

El artificio, en constante pugna con lo auténtico, impide a Esteban satisfacer su ideal de creador. Sin embargo, ese tratamiento de sistema inconcluso otorga a la novela los medios para transmitir la nostalgia de quien aspira a forjar algo que valga la pena 
antes de fallecer. La voz narrativa despierta un sentimiento de lo sublime cuando hace palpable que morir implica perder la capacidad de crear y atestiguar la casa perdida en la espesura del follaje:

Yo trabajaba desde que empezaba la luz hasta que terminaba. La muerte, a mi edad, bien podría estar rondándome de cerca, pero no era eso lo que me asustaba. Me obsesionaba la idea de que si no terminaba lo que había emprendido o lo terminaba mal, iba a ocurrir algo malo, atroz quizás (p. IoI).

El afán por terminar su proyecto, siempre amenazado por la causalidad inusitada de la destrucción, lo atormenta: "cualquier cosa nos puede pasar siempre en cualquier momento. Bajo cada piedra, detrás de cada árbol acecha el espanto” (p. 102). Es así que se siente la profundidad abisal de la muerte; no obstante, la necesidad de habitar ese paraíso revela un carácter de "utopía moderna donde el citadino deposita sus últimas ilusiones. En el paisaje hostil y contaminado de la urbe actual, el jardín se transforma en un espacio de ensoñación y de trascendencia" (Salamanca, 2019, p. 239). Contrario a la ciudad que supera sus capacidades, el jardín permite moldear un espacio y proyectar una forma de entender el mundo, una identidad y posición política. Este lugar escapa al control del gobierno y funciona bajo las reglas que imparte su dueño; solo él decide qué hacer en el pequeño terreno. En consecuencia, lejos de ser un topónimo tradicional, actúa como una heterotopia (en el sentido foucaultiano), un espacio con fuerzas que constituyen una nueva lógica donde se da "el poder de yuxtaponer en un solo lugar físico varios espacios que sean diferentes entre sí, de tal manera que formen un microcosmos en su interior" (ToroZambrano, 2017, p. 38). Así mismo, las relaciones que lo configuran "mediante objetos, colores, formas, palabras, sonidos [...] permiten que el espacio cambie. Esto hace que los múltiples lugares [que lo integran] sean contradictorios con el lugar" (p.38) que los rodea.

El jardín es, entonces, un elemento beterotópico de crisis o desviación, es decir, un emplazamiento habitado por quien huye de la sociedad y se comporta críticamente frente a ella, aunque derive de esta. Fuera de los órdenes establecidos, las dinámicas humanas que comporta lo convierten en un contraespacio, una oposición al encierro de los geriátricos u hospitales (sitios a los cuales se liga la vejez). Aunque es localizable en términos geográficos, el jardín permite alejarse de la inactividad inherente a la jubilación e impugna los imaginarios tradicionales sobre las virtudes que envuelve el distanciamiento social. Al plantar flores y llevar una vida activa, incluso en lo sexual, 
Esteban desmiente el destino de quietud que envuelve la ancianidad, y reconfigura la episteme en torno la proximidad de la muerte. Sus ideales discuten con los escenarios de dominación discursiva que ocultan el espectro infinito de lo mortuorio y se soslayan en el paradigma de representación colombiano, inscrito en el duelo judeocristiano.

Ahora bien, la enunciada ventaja de la horticultura (ocupar el cuerpo y el espíritu) asemeja las conductas de Esteban a las de quien se interna entre las plantas en Los caballitos del diablo, con un propósito, sentirse parte de la tierra, pues "la vida sin emprender nada es la muerte"(González, 2018, p. 201). Tal tarea requiere suspender el "yo" para integrarse al entorno; actitud asociada con la filosofía budista practicada por Esteban con la cual busca liberarse del sufrimiento, encontrar un equilibrio entre el vacío y, para nuestro caso, lo cultivable, a partir de la meditación. La necesidad de paz y armonía será una meta inalcanzable, debido al recurrente malestar físico que los afecta. En el caso del "El":

Por fin se le quitaron los mareos que le dieron después de que los médicos le cortaron los nervios del estómago, pero a veces empezaba a sentirse repleto exactamente hora y media después de las comidas, como si acabara de comer mucho, y la náusea lo hacía vomitar chorros de bilis, a veces verde, a veces amarilla (González, 2003, p. 64).

Por su parte, Esteban sufre una molestia diferente: "Y había ahora también lo del dolor de cara que me ponía a tomar analgésicos inútiles y a hacer buches de aguasal que servían tan poco como los analgésicos. Y estaba lo del insomnio, cada vez más grave” (p. 72). Malestar que lo empujó a pensar en el suicidio, al considerar que la vida "duraba demasiado y empezaba a ser repetitiva como el latido del corazón, y de eso ni la armonía de las plantas alcanzaba" (p. 72) para salvarlo. Su estado de salud ratifica al jardín como un refugio para dilatar la muerte. De esta forma, Las noches todas ofrece una experiencia que afecta al lector porque esboza una etapa futura o presente de su vida.

González no refiere a la muerte solo a través del cadáver, él cuestiona su presencia, su inminencia. Los personajes luchan por sus deseos y metas, mientras se despojan de aquello que los une al mundo. La hondura de la muerte valora cada brizna y cada grieta para expresar su trascendencia. A pesar del dolor en el maxilar que le impide dormir y lo hace alucinar que Aurora seduce a otros hombres o que él ha peleado con su exmujer, la meta de Esteban permanece intacta. El alivio a sus tormentosos días yace en la contemplación del paisaje, en la beldad del cuerpo de Aurora y en la astucia 
de Misael. Aunque parezcan superfluas, las vicisitudes humanas y su contraste natural denotan un mundo que sin la aflicción estaría incompleto, y sería tan poco armonioso como un jardín artificial donde falta un espíritu:

Mi ambición ahora, también exagerada, poco razonable, poco cuerda, era que las personas que recorrieran el jardín sintieran con toda claridad, o mejor, vieran, que la vegetación terminaría por alcanzar en aquel lugar, con el paso de los siglos, la destrucción completa de todo trazo humano y el regreso a la selva prístina, oscura, indivisible original (González, 2018, p. 103).

La naturaleza descubre las carencias del ser y en el inútil control sobre el destino, desmitifica el poder siniestro de la muerte. Esteban asume la mortalidad como un hecho irrebasable y le quita el velo de dolor; al saberse finito, solo anhela participar en la germinación de la vida, creando un pequeño cosmos. Tal reconocimiento de la ausencia como necesidad deja ver que la felicidad está en reconocer la cercanía de la extinción. La novela termina con Esteban vendiendo su edén a una constructora, y ante la conclusión del proyecto, inicia otro sueño: ser apicultor. El jardín se transfigura en la nostalgia de la arcadia perdida, aquel sitio que no puede mantenerse intacto y que es mejor olvidar. Con el dinero de la venta se acomoda en un hogar de retiro y después se muda a un pequeño pueblo para cuidar abejas y preparar miel. Tomás González asume el sentido básico de la muerte: el final de la existencia. Al establecer paralelos entre la vegetación y el austero tiempo que le resta al protagonista, excede el hecho en sí y trasciende el duelo personal, porque si Esteban muere, no se modifica el orden del mundo.
Años no es lo que hay. Mientras menos van quedando mayor es mi admiración por haber tenido uñas, pestañas, rótulas; por haber estado aquí y porque todo el mundo me llame Esteban [...] porque algunas cosas tengan nombre y la infinita mayoría no lo tenga; porque lo luminoso fluya hacia lo oscuro, y porque lo grande y lo pequeño fluyan siempre hacia lo que no tiene tamaño (González, 2018, p. 210).

La muerte, más allá de la nostalgia, asume el prisma alegre de ser un desenlace apropiado para alguien que hizo todo lo que quería. Esteban siente plenitud porque es el único resultado que puede alcanzar. Al estar viejo todo se le va borrando, la ambición de nuevas metas por emprender, las culpas de lo que no hizo bien durante su vida y, de esa manera, regresa a la infancia, a ese periodo donde habita la inocencia que se vuelve absoluta con 
la muerte. Aunque la novela no finaliza con su deceso, se dibuja cercano, mientras él observa la oscuridad en la cual se consume su existir, al igual que las noches todas.

\section{Memorias de un hombre feliz}

La novela presenta la vida de Tomás, un ingeniero que llega a la empresa de los García. Allí conoce a Regina e inicia una relación de la que no tiene control. Tras varias décadas de ser un padre y marido ejemplar, se percata de la falsedad que lo rodea y decide matar a su esposa. Tan pronto logra su cometido, recupera su autonomía y la intención de ser feliz, mientras dedica su jubilación a construir relojes.

Con críticas a las formas de vida actual, caracterizadas por el enriquecimiento de ciertas elites y la segregación, el libro retrata una sociedad esnobista; mujeres adineradas preocupadas por la dieta que está de moda y hombres interesados en mantener el ascenso de las compañías familiares revelan el deterioro de los valores y la perdida de empatía. Tomás, hastiado de aquel mundo y con un odio visceral por su mujer, emprende la tarea de precisar los días y horas en que viajó, asistió a fiestas, celebró aniversarios o acudió a reuniones; actividades que lo expropiaron del libre albedrío y lo condujeron a ver en el asesinato una vía para retomar el control. Como resultado, la novela plantea dos dimensiones: la satírica hacia los valores de la sociedad, y la cínica en la actitud adoptada por los personajes.

Dos personajes cobran relevancia en la toma de consciencia del protagonista. Por un lado está Diva Tarcisia, de una "avasallante personalidad [que] le permitía salir cada mañana a la conquista del mundo" (Jaramillo Agudelo, 2010, p. 91). Ella, junto a la asidua tropa de visitantes que concurrían a la casa del matrimonio García, recibía clases privadas sobre Lyotard y la posmodernidad, lo que "transformaba a las damas [...] en salvadoras de los desamparados" (p. 121). No obstante, su personalidad está marcada por el influjo de Regina:

Sin ejercer un explícito autoritarismo, Regina controlaba su entorno en términos absolutos. Nada se le escapaba. Construía a su antojo a la gente que le rodeaba e imponía su voluntad con una fuerza tan irresistible, que podía darse el lujo de las buenas maneras, de la cortesía. Diva Tarcisia no escapa a ese reinado absoluto. Sin duda, la Diva Tarcisia de Regina fue moldeada por la misma Regina. Y, a lo mejor, con inteligencia y perversidad, la diseñó como un íncubo (p. IIo). 
El resultado es una marioneta controlada por quien administra su hogar y el entorno cercano, con poder absoluto. Por otro lado, está Pedro Roberto. A diferencia de su amigo, él tiene autonomía para tomar sus decisiones:

A las diez y dos minutos vi el plato que Regina escogió "con las cosas que más te gustan". En ese mismo instante regresó Roberto del bufet con su propio plato, escogido y servido por él mismo entre las variadas posibilidades del mostrador (p. 219).

En complemento, líneas más adelante agrega: “cuando examiné el plato de Pedro Roberto, supe con certeza que tenía el menú que yo hubiera escogido para mí”. Al evidenciar el contraste manipulación-libertad, visible en otros, Tomás examina si sus gustos, metas y sueños, eso que damos en llamar personalidad, es algo constituido por sí mismo o es derivado de controles externos: "Hoy me parece la prueba más evidente de que yo no existía. Mi rutina diaria estaba tan absolutamente codificada, programada [...] automáticamente repetía los mismos movimientos diarios bajo la confianza - o terror - adicional de que alguien, Regina, los controlaba” (p. 147). El formato testimonial concede al protagonista la oportunidad de medir la importancia de algunos sucesos, bajo una configuración temporal que cuestiona lo que ya hizo o piensa hacer: "vuelvo al presente [...] porque sólo aquí, en estas memorias de un hombre feliz, puedo consignar mis pensamientos sobre algo que ocurrió esta mañana” (p. 149). Tal visión del tiempo genera una nueva disposición del personaje, trastoca su sentir y lo libera de un porvenir signado por la supresión: "Presiento que si no viene por mí de súbito, moriré cuando no pueda hacer las cosas que me gusta hacer. Entonces, mi feliz estadía en este planeta ya no tendrá sentido y me dejaré morir" (p.149). Lo anterior nos recuerda a Redeker (2018) y sus apreciaciones respecto a cómo asumir la vida:

Quizás solo soportamos esta historia que es nuestra vida (Eros) porque sabemos que ella terminará (Tánatos): el saber de la muerte, así como lo sugirió Lacan, es entonces lo que hace aceptable la vida. El reto no es tanto el de aceptar la muerte como el de aceptar la vida (p. 27).

El razonar de Tomás deconstruye los imaginarios de la muerte y la sitúa como etapa final del largo camino que suscita existir. Para llegar a tal alternancia, el personaje experimenta dos decesos: el de su esposa y el propio (matar el “yo” creado por Regina); situación que antepone un debate ético, pues la operación de traslación entre el cuerpo 
enfermo de Regina y la edificación personal de Tomás supone preguntarse en virtud o a costa de qué se alcanza la felicidad.

Esta mañana me volvió a ocurrir. Salgo de la casa a mi caminada matutina y, en el mismo instante en que cierro la puerta - ahora veo mi mano sobre el pomo-, me viene un sacudimiento, una especie de cosquilleo indeterminado, la sensación de haber olvidado algo, bien conocida por usted y por mí, y que suele corresponder a un hecho cierto (Jaramillo Agudelo, 2010, p. 9).

La sensación referida es el embate psicológico causado por matar a su esposa; acción que modifica el edicto católico: “juntos hasta la muerte”. Lo que para Regina constituye una relación inmejorable, para Tomás es un castigo que lo lleva a contemplar tres caminos: divorcio, suicidio y asesinato. Para el primer caso, "resultaba muy difícil hallar una causal verosímil de divorcio [...] ningún testigo corroboraría que yo fuera muy coherente si afirmaba que no podría aguantar a Regina” (p. 230). Por su parte, suicidarse lo "sacaba, no a la vindicta de Regina como el divorcio, sino más expeditamente a la nada" (p. 231). En cuanto a elegir el homicidio para evitar el enfrentamiento que ocasiona el separarse, contradice la percepción de Tomás sobre el contexto de apariencias que habita. La resistencia a enfrentar la opinión pública manifiesta un rechazo a perder su estilo de vida privilegiado; poco pesa tener otras alternativas, pues se deja llevar por una pasión que niega toda concepción moral o ética, y permite explicar la conducta de los personajes, en términos freudianos, con la oscilación entre pulsión de vida y muerte. Mientras el proceder de Regina afirma una matriarca blindada contra el dolor y escindida del peligro, su esposo arma un plan para desestimar ese arquetipo. Retomando a Dylan Evans (2013),

\footnotetext{
"La distinción entre pulsión de vida y pulsión de muerte es verdadera en cuanto pone de manifiesto dos aspectos de la pulsión" [...] Por consiguiente, "toda pulsión es virtualmente una pulsión de muerte" [...] porque I) toda pulsión persigue su propia extinción, y 2) toda pulsión es un intento de ir más allá del principio de placer, hasta el reino del goce excesivo, en el que es experimentado como sufrimiento (p. I6o).
}

En este sentido, al dar aspirinas a su esposa, alérgica a este medicamento, se erige un sentimiento de plenitud que, a diferencia de lo anotado por Evans retomando a Lacan, no genera remordimiento porque la desconexión entre Tomás y Regina es,irónicamente, 
la forma en que él conserva su vida. Al respecto, cabe aclarar que para Sigmund Freud (1981) el placer es un elemento de la pulsión de vida (Eros), mientras la abolición caracteriza su contrario (Tánatos); por tanto, en Tomás ambas pulsiones están ligadas en diferentes proporciones. Ahora bien, asumir que el morir, propio o ajeno, produce sentimientos diferentes al dolor no resulta descabellado en la cultura occidental donde, por ejemplo, se asocia el orgasmo sexual con "una pequeña muerte". En ese efímero acto se anula la noción de ser (una pareja se convierte en uno solo, cuando se conectan en la intimidad). Con todo ello, inconscientemente, negamos otras relaciones entre ambos sucesos. En Tomás, lo tanático equivale a un estímulo; las pastillas que da a Regina lo llenan de satisfacción, mientras destruyen la salud de aquella.

Al focalizar al victimario, Jaramillo Agudelo manipula los discursos cotidianos de la muerte. El tono confidente de la voz narrativa genera familiaridad con el lector, para congraciarlo con Tomás. Situar como antecedentes del macabro accionar, el autoritarismo, la sobreprotección y el secuestro de su identidad, tornan a la víctima en verdugo y transmutan al victimario en mártir. Configuración que se defiende en reiteradas ocasiones, a través del monólogo interno:

Esta es la historia de cómo asesiné a mi esposa, si bien aquí no se trata de una confesión y en términos oficiales no puede hablarse de asesinato. Es más, existe un certificado médico que explica las causas naturales que la llevaron a su tumba (Jaramillo Agudelo, 2010, p. II).

La anormal situación se torna más confusa cuando Tomás afirma, con cierta hipocresía: "me inquieta que piensen que estoy recomendando el asesinato como fórmula para la felicidad. No es así de simple. Ante todo no propongo el asesinato y, luego, no creo que el asesinato sea la fórmula de la felicidad” (p. 275). A pesar de los argumentos egoístas que sustentan el crimen, no se conmueve por el bienestar de sus hijos, el cariño de familiares o los años compartidos junto a su pareja:

El horror metafísico al descubrir un ser ajeno entre mi pellejo me impulsó a prescindir de su autora. Era la única manera de expulsarlo y de permitirle al verdadero y latente Tomás que sobreviviera. Ahí se ve con claridad: era su vida o la mía. La eliminé en defensa propia. Esto lo sé ahora más que nunca, cuando soy un ser satisfecho, sereno y feliz (p. 73). 
Si bien su caso es similar al formulado por R. L. Stevenson (1886) en Dr. Jekyll y $M r$. Hide - dos seres (un monstruo y un científico con un alto grado de neurosis) habitando un mismo cuerpo-, Tomás no padecerá una transformación física, pero sí se convertirá en un ser esquizoide, fragmentado en dos: "Entonces me di cuenta. Existía otro Tomás debajo del que Regina había inventado. O latente" (Jaramillo Agudelo, 2000, p. 220). Como resultado, además de matar a su creadora, aparece en escena un suicidio simbólico.

Un Tomás nuevo u oculto durante años, un Tomás que era - a lo peor - una mera caricatura de aquel que mi mujer diseñara para su uso doméstico, le soltaba frases a este último en una conversación que transcurría silenciosa dentro de mi pellejo: "Admite que no soportas a Regina" (p. 22I).

Fundado en la idea de que destruir la gran cabeza de los García es rescatarse a sí mismo, su bienestar revela un contrasentido: el deceso de Regina acarrea el suyo. Tal circunstancia contradice la hipótesis freudiana: "la total vida instintiva sirve para llevar al ser viviente hacia la muerte" (Freud, 1981, p. 2119), pues eliminar una parte de su forma de ser no implica un perecer del cuerpo en el sentido físico. Bajo esta línea de sentido, "la misteriosa e inexplicable tendencia del organismo a afirmarse en contra del mundo entero desaparece, y solo queda el hecho de que el organismo no quiere morir sino a su manera” (p. 2119). Los instintos de conservación que rigen al protagonista son intuiciones parciales del yo, aseguran su camino a la muerte bajo aspiraciones personales y no con el tinte dramático que hubiese forjado el matrimonio. Siguiendo la postura de Hélène Pouliquen (2018),

El narrador, venciendo la represión de manera provocadora, se atreve a mencionar, como fruto de un crimen "una satisfacción plena y entera [...], sin reservas, un placer sin límites [...], el acmé de un placer sin trabas en que el sujeto se extasía (pp. 103-104).

En este sentido, Tomás emprende una búsqueda que, además del anhelo por recobrar la autonomía perdida, se alimenta de la venganza. Su construcción interior no se relaciona con lo físico, sino con el deseo de ser feliz. Tal visión de la plenitud se mueve en un espectro en el que "el goce puede ser producido por lo que, en principio, está en sus antípodas: el dolor” (p. 104). Por tanto, es lícito pensar que el deseo de felicidad habita en todas las personas, pero la manera de concretar tal aspiración, según Lyotard (1998), posee diversos caminos: 
Lo bello da un placer positivo. Pero hay otra clase de placer, ligado a una pasión más intensa que la satisfacción, que es el dolor y la cercanía a la muerte. En el dolor, el cuerpo afecta el alma. Pero esta también puede afectar a aquel, como si el cuerpo experimentara un dolor de origen externo, por el solo medio de representaciones asociadas inconscientemente a situaciones dolorosas (p. 104).

De modo que Jaramillo Agudelo revela que más allá de considerar dolorosa la muerte, la ve como un peldaño a superar, e invita a cuestionar cómo el imaginario colectivo colombiano no discute la muerte en contextos concretos como la guerra y evidencia que existe una deuda filosófica para con ese destino.

El autor postula lo crucial de perseguir una libertad cuya génesis esté en la interioridad del héroe y no en las reglas impuestas por el entorno. Su novela percibe la muerte como instante posible de plenitud, al comprender que el placer reside en el bienestar personal y en la supresión de los entes dañinos que alteren dicho estado. Tomás vive una metamorfosis; mientras uno de sus dos seres muere, el otro se yergue triunfante y demuestra que la vida contiene diversos elementos que se fusionan en diferentes niveles, dependiendo las experiencias individuales.

Una aspirina, un accidente de carro o una larga enfermedad son suficientes para conducirnos a la muerte. Ante tal noción, ¿por qué no buscar una redención de tal inminencia con caminos más alentadores? La decisión radical de Tomás cuestiona al lector sobre si alcanzar la felicidad admite el ejercicio de un crimen. El placer de ver a su esposa fallecer levantó en él un espíritu altivo y lo internó en una labor minuciosa en la que fue olvidando, progresivamente, la noción de las horas y los minutos; perderse entre relojes lo hizo feliz, y es necesario creer tal verdad, pues sus memorias así lo comprueban.

\section{Conclusiones}

Las reflexiones de Tomás González y Darío Jaramillo Agudelo superan la realidad trágica que soporta la muerte en Colombia, e incorporan la plenitud como circunstancia constitutiva de los momentos de crisis. La exuberancia resguardada en un pequeño jardín o la sutileza con que un hombre mata a su esposa invitan al lector a revisar si existe felicidad en la sorda brutalidad del hecho. El énfasis 
en las biografías de dos ancianos revela emociones soñadas y perdidas; más que describir su existir, las novelas reflexionan acerca del sentir humano que, apoyado en el artificio literario, consuma una poética del morir.

En un país donde la muerte se conserva en un pedestal y poco se discute su presencia o se analiza su incidencia en las letras, resulta esencial verla como destino manifiesto. Admitir su inminencia permite concebir la vida como posibilidad abierta. Más que ocultar la tristeza o proponer una elegía al dolor, las novelas configuran una experiencia de la muerte que ordena su visión de mundo y determina las conductas nerviosas de los personajes. A partir de esta línea de sentido, es posible concluir la imperiosa necesidad de emprender su exégesis. No podemos omitir que los personajes de ficción encarnan la condición humana, nadie se libra de lo que es propio de ser hombre, incluso cuando esa humanidad es ficticia.

El problema para iniciar una historia de la muerte en la literatura colombiana y habilitar nuevas posturas está en avizorar la envergadura de la iniciativa, el volumen del análisis y los retos de formular criterios, no siempre justificables, de inclusión y exclusión. En Hacia una historia de la literatura latinoamericana (1987), Ana Pizarro señala los desafíos de emprender tal travesía. Si bien sus ideas se dan a nivel continental, permiten dimensionar la heterogeneidad que circunda un territorio y responder algunos interrogantes en cuanto a qué entender por literatura colombiana; así mismo, qué tratamiento de la muerte es idóneo al contemplar categorías analíticas y plantear investigaciones. Tales problemas refieren a la delimitación de una zona literaria, y urge responderlos en aras de constituir una "colombianidad" frente al tema.

El país ha tenido conflictos de gran envergadura que recién empiezan a aquilatar un proceso de transición. Existen muertes sin cuerpos, cadáveres amontonados en fosas comunes, familiares que no han podido ser despedidos. Aún hay anécdotas sin contarse, actitudes que no han sido trabajadas y enfoques que no han visto la luz. Es deber de la historia literaria descubrir y reconocer esas alternativas al escepticismo. Las novelas de González y Jaramillo Agudelo ejemplifican el potencial análisis. Lejos de concebir la muerte como un suceso donde hay extinción, iniciar su exegesis no busca romantizar el suceso, más bien se trata de aprender a reaccionar y estar cerca de ella. 


\section{Referencias bibliográficas}

Báez León, J. A. (2013). Dos novelas de Tomás González. Cuadernos de literatura 14 (27), pp. 200-223. Campo Becerra, O. D. (2012). Naranjas en el suelo. La conciencia de la muerte en la obra de Tomás González. Literatura: teoría, bistoria, crítica 14 (1), pp. 159-182.

Evans, D. (2013). Diccionario introductorio de Psicoanálisis lacaniano. Buenos Aires: Paidós. Freud, S. (1981). Obras completas. Tomo II - III. Madrid: Biblioteca Nueva.

Goldman, L. (1971). La sociología y la literatura: situación actual y problemas de método. En Sociología de la creación literaria (pp. 10-43). Buenos Aires: Buena Visión.

González, T. (2003). Los caballitos del diablo. Bogotá: Seix Barral.

González, T. (2018). Las noches todas. Bogotá: Seix Barral.

Heidegger, M. (1993). El ser y el tiempo. Bogotá: Fondo de Cultura Económica.

Jaramillo Agudelo, D. (2010). Memorias de un hombre feliz. España: Editorial Pre-Textos.

Lederach, J. P. (2016). La imaginación moral. El arte y el alma de la construcción de la paz. Bogotá: Semana Libros.

Lyotard, J. F. (1998). Lo inhumano: charlas sobre el tiempo. Buenos Aires: Manantial.

Montaigne, M. (1984). Montaigne. Ensayos completos. Tomo I. España: Ediciones Orbis S. A.

Nietzsche, F. (2011). Así habló Zaratustra. España: Alianza Editorial.

Pouliquen, H. (2018). La novela del encanto de la interioridad: literatura, filosofía, psicoanálisis. Bogotá: Editorial Pontificia Universidad Javeriana, Instituto Caro y Cuervo.

Quintana, P. y Díaz S. (2018). "Uno está en total libertad de hacer lo que le dé la gana": Tomás González. Entrevista. Revista Arcadia 27. Recuperado de: https://bit.ly/3cUycGJ [28.05.2020].

Redeker, R. (2018). El eclipse de la muerte. Bogotá: Fondo de Cultura Económica.

Ruiz Vásquez, N. (2014). Léxico de la muerte en el español hablado en Colombia. Bogotá: Instituto Caro y Cuervo.

Salamanca, N. (2020). El jardín y otros espacios vitales en la obra de Tomás González. Estudios de Literatura Colombiana 46, pp. 233-242. DOI: 10.17533/udea.elc.n46a12

Saiz Galdós. J., Fernández Ruíz, B y Álvaro Estramiana, J. L. (2007). De Moscovici a Jung: el arquetipo femenino y su iconografía. Althenea Digital 11, pp. 132-148. DOI: $10.5565 / \mathrm{rev} / \mathrm{athenead} / \mathrm{v} 0 \mathrm{n} 11.385$

Toro-Zambrano, M. C. (2017). El concepto de heterotopía en Michel Foucault. Cuestiones de filosofía 3 (21), pp. 19-41. DOI: 10.19053/01235095.v3.n21.2017.7707 